\title{
Experimental investigation of acid mining water
}

\author{
Martin Pushkarov ${ }^{1}$, and Rositsa Velichkova ${ }^{1 *}$ \\ ${ }^{1}$ Technical University of Sofia, Department Hydroaerodynamics and hydraulic machines, 1000 Sofia, \\ Bulgaria
}

\begin{abstract}
In presented work is made an experimental study for purification of mining water. Depending on the specific requirements, the required methodology is used. It is made an analysis of the obtain results. Experimental studies to determine the levels of purification of impurities monitored in the treated mine water depending on the chosen method for their treatment were conducted on the basis of the compared results for the content of monitored pollutants - mainly insoluble substances, iron, manganese and metal cations.
\end{abstract}

\section{Introduction}

Acid mine water (AMW) is considered to be the biggest environmental problem associated with mining. This phenomenon is related to the oxidation of pyrite and other sulphide minerals, resulting in acidic water containing sulfuric acid, dissolved heavy metals, and suspended iron sludge's in the environment (Table 1). The main sources of acidic mines are open and underground mines, deposits of rock and poor mining's, industrial waste, staining sulfide concentrates, and pyrite-rich coal and uranium mines. In addition to iron and other heavy metals, acidic uranium mining mines contain radioactive elements such as uranium and radium. Toxic elements such as arsenic and antimony are other essential components of acidic mineral waters dissolved from mineral materials containing these elements. [1-4].

The mixing of acid mine waters with natural river and lake waters causes a serious deterioration of the quality of the latter. Such polluted waters are unsuitable for most aquatic organisms, for human consumption and for industrial purposes. Soils along the water path are also contaminated and become unusable for agricultural purposes. [3].

Table 1. AMW from different mines.

\begin{tabular}{|c|c|c|c|}
\hline Index & $\begin{array}{c}\text { AMW from } \\
\text { uranium mine }\end{array}$ & $\begin{array}{c}\text { AMW from } \\
\text { copper mine }\end{array}$ & $\begin{array}{c}\text { AMW from coal } \\
\text { mine }\end{array}$ \\
\hline $\mathrm{pH}$ & $2,71-4,10$ & $2,8-4,5$ & $1,45-2,03$ \\
\hline $\begin{array}{c}\text { Sulfates, } \\
\mathrm{mg} / \mathrm{l}\end{array}$ & $361-1520$ & $824-1540$ & $3250-8141$ \\
\hline $\mathrm{Fe}, \mathrm{mg} / \mathrm{l}$ & $91-1070$ & $145-325$ & $1142-3074$ \\
\hline $\mathrm{Mn}, \mathrm{mg} / \mathrm{l}$ & $1,9-44$ & $0,80-8,20$ & $32-95$ \\
\hline $\mathrm{Cu}, \mathrm{mg} / \mathrm{l}$ & $1,04-12,5$ & $2,84-17,0$ & $0,07-0,19$ \\
\hline $\mathrm{Zn}, \mathrm{mg} / 1$ & $1,90-24,4$ & $4,10-12,5$ & $0,14-0,41$ \\
\hline
\end{tabular}




\begin{tabular}{|c|c|c|c|}
$\mathrm{Cd}, \mathrm{mg} / 1$ & $0,02-0,10$ & $0,15-1,20$ & $0,02-0,08$ \\
\hline $\mathrm{Pb}, \mathrm{mg} / \mathrm{l}$ & $0,15-0,7$ & $0,08-0,41$ & $0,05-0,15$ \\
\hline $\mathrm{As}, \mathrm{mg} / 1$ & $0,01-0,32$ & $0,37-2,80$ & $0,01-0,14$ \\
\hline $\mathrm{U}, \mathrm{mg} / 1$ & $0,44-2,80$ & - & - \\
\hline $\mathrm{Ra}, \mathrm{mg} / 1$ & $0,08-0,45$ & - & - \\
\hline
\end{tabular}

In the last few years, mining companies have faced a number of challenges - the requirements for environmental protection and the effective management of valuable resources such as water, as well as stringent legislative rules in these areas.

Although most of the waste generated by the mines is in the solid state, the main pollutants from the extraction and processing activities are separated by the wastewater. It is estimated that over $70 \%$ of the pollutants from the mining industry are emitted into the water, which necessitates the application of various technologies to purify these streams be mining they are released into the environment.

It is critical not to allow the release of toxic components from the mining into the environment, as this would subsequently lead to their entry into the food chain. There for mining, the requirements to be met by the discharged water flows become mining stringent, and non-compliance with the set norms is punished by increasing fines.

Similar investigations are made in [5-10].

Wastewater can emit reagents from the processing of minerals such as cyanides, acids and bases, solid or dissolved metal compounds, dissolved salts, radioactive components, chlorides and suspended particles [11,12].

\section{Experimental test-rig}

Experimental test - rig is presented at Fig.1. Principle of work is as follow: A sample cabinet where is store the samples which will be tested. The samples themselves are poured into flasks (sample container $\varnothing 300 \times 500$ ) with a specific amount of water taken from the studied mine. Place the flasks at the top of the sample cabinet and place them in their respective positions. A stand is lowered on them with stirrers mounted on it, which stir the water at a specific time, in a specific way. The mixing of the samples with and without the addition of flocculant, lime milk, sulfuric acid $\left(\mathrm{H}_{2} \mathrm{SO}_{4}\right)$, etc., is monitored by the laboratory assistant, detecting the time for precipitation of elements at the bottom of the flask (sample vessel $\varnothing 300 \times 500$ ). The $\mathrm{pH}$ of the water (on all samples) is periodically measured from the $\mathrm{pH}$ meter mounted on the stirrer frame. After separating the sediment at the bottom of the vessel (Ø300x500), a sample is taken from the sediment and a chemical analysis is performed (the same applies to the remaining clear layer of water above the sediment). Experiments are performed on each of the additives used in this work, such as flocculants, lime milk and sulfuric acid, as the main idea is to accelerate the time of separation of metals in the form of sediment and increase the $\mathrm{pH}$ of water. 


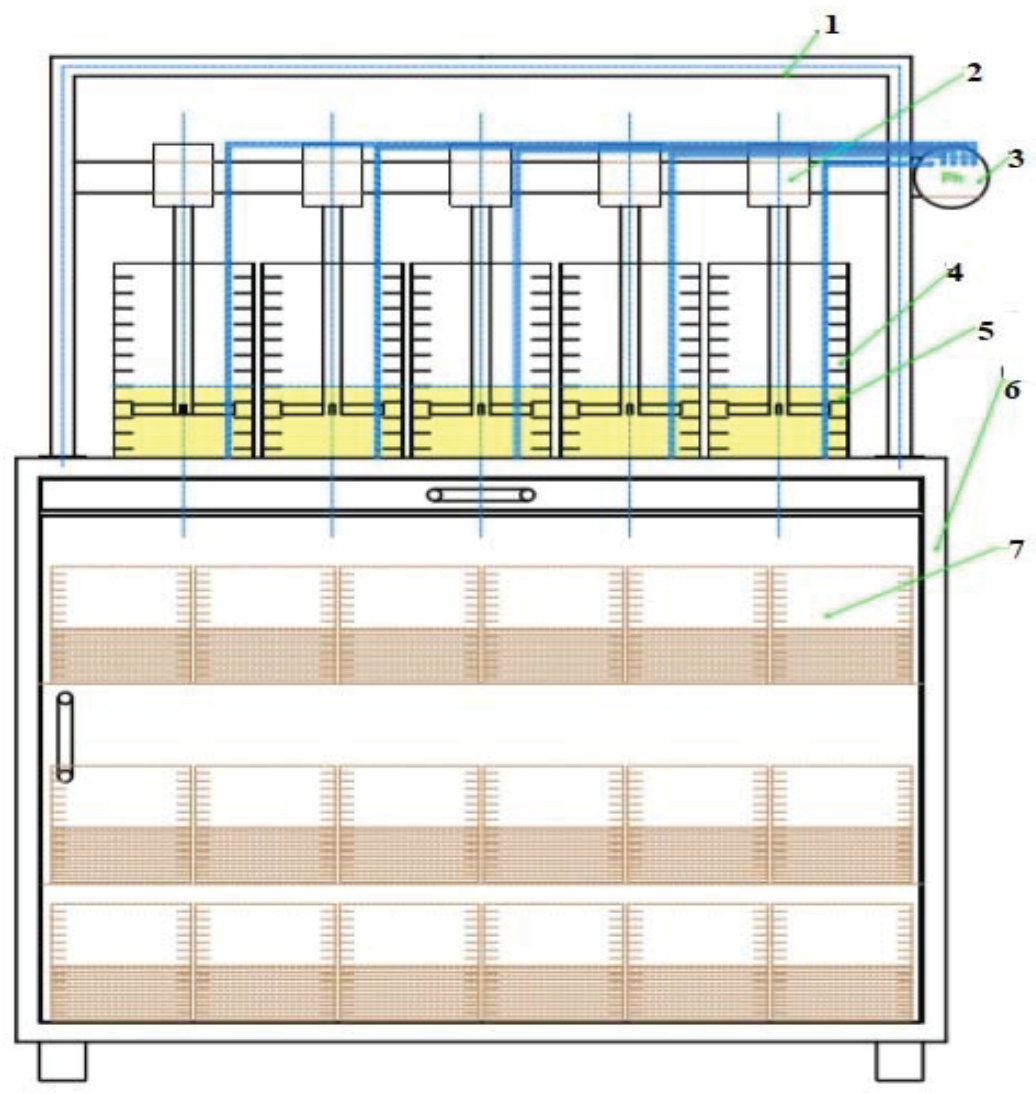

Figure 1 - Scheme of the test rig: 1-Frame; 2- Stirrer; 3-pH meter; 4-Vessel for sample;5,7 - Sample, 6 - Sample Container;

\section{Results from the experimental investigation}

The results of the performed laboratory tests for direct determination of the levels of neutralization with lime milk ( $10 \%$ suspension) and sodium base (10\% solution) of the acid mine waters to the values of the active reaction $\mathrm{pH}$ from 9,5 to 11, showing the achievement of the maximum possible degrees of desulphation and corresponding coprecipitation of the metal cations in the hydrate precipitate are is shown at fig.2.

The results of laboratory tests to determine the levels of desulphation of acid mine waters with different neutralizing reagents to values of the active $\mathrm{pH}$ reaction to achieve maximum possible co-precipitation of the metal cations contained in them, show that their neutralization (at initial $\mathrm{pH}$ about 3,3 for with $10 \%$ lime milk and about 2,9 when conducted with $10 \%$ sodium hydroxide solution) proceeds normally at levels around pH-9,2 and 11 and $\mathrm{pH} 10$ and 10,95 for lime milk and sodium basis, respectively. However, at final $\mathrm{pH}$ levels of the order of 10,30, the neutralization of acidic waters with lime milk is delayed in time in the range of $10-10,30$, probably due to the formation of said acid salts of the type Mex $(\mathrm{OH})$ y $\left(\mathrm{SO}_{4}\right) \mathrm{z}$ and slowing down the whole desulphation process. This is also evident from the nature of the curves shown in Figure 2. For all curves, except for that of Sample 2, a stabilization of the level of the active reaction $\mathrm{pH}$ of the desulfatized subjects from 10 to 18 minutes is reported, and for the quoted sample a significantly longer period of time is reported. In practice, this shows that when it is necessary to select a level for 
desulphation in an active reaction of $\mathrm{pH}$ around 10, the selection and sizing of the equipment for this process must be carefully approached, taking into account the above. Experience has shown that in order to overcome this problem, it is necessary to provide for carrying out the process in several successive stages in different chambers with the appropriate properly selected mixing and feeding of the working solution from the used flocculant.

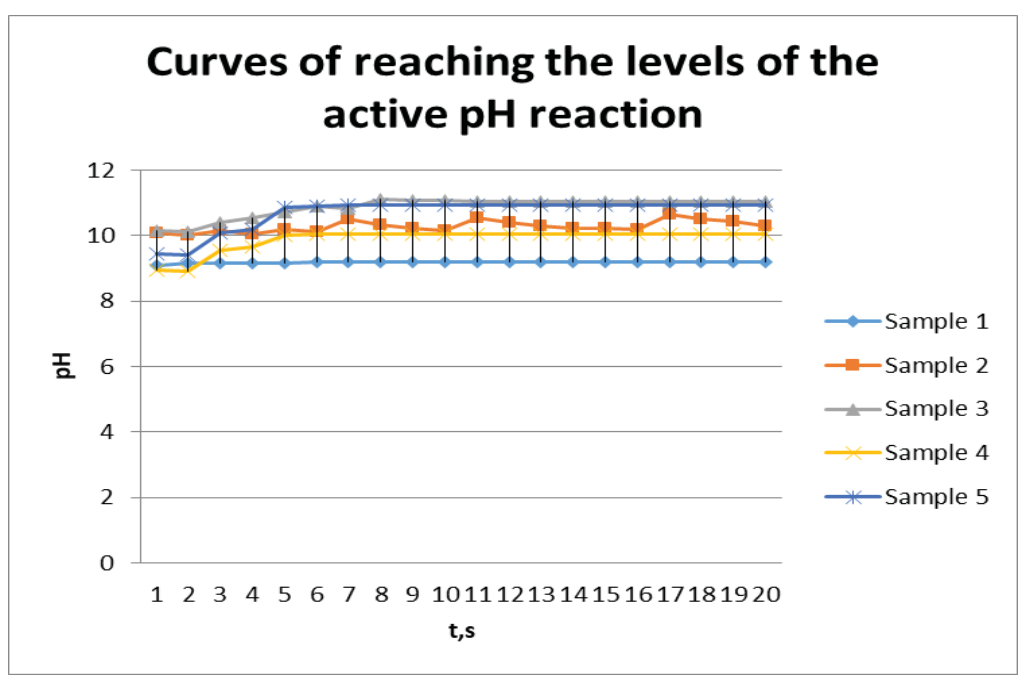

Figure 2 - Curves of reaching the levels of the active $\mathrm{pH}$ reaction

Figure 3-7 shows the content of the following components - insoluble substances, hardness and metals in $\left(\mathrm{mg} / \mathrm{dm}^{3}\right)$ determined analytically in samples of treated water after neutralization of acid mine water with lime milk (samples 1-3) and sodium hydroxide. (samples 4-5) to different levels of active $\mathrm{pH}$ reaction and subsequent treatment of the anionic flocculant MAGNAFLOC338 - $2 \mathrm{mg} / \mathrm{dm}^{3}$ in order to achieve the maximum possible co-precipitation of the metal cations in them in the form of hydroxides.

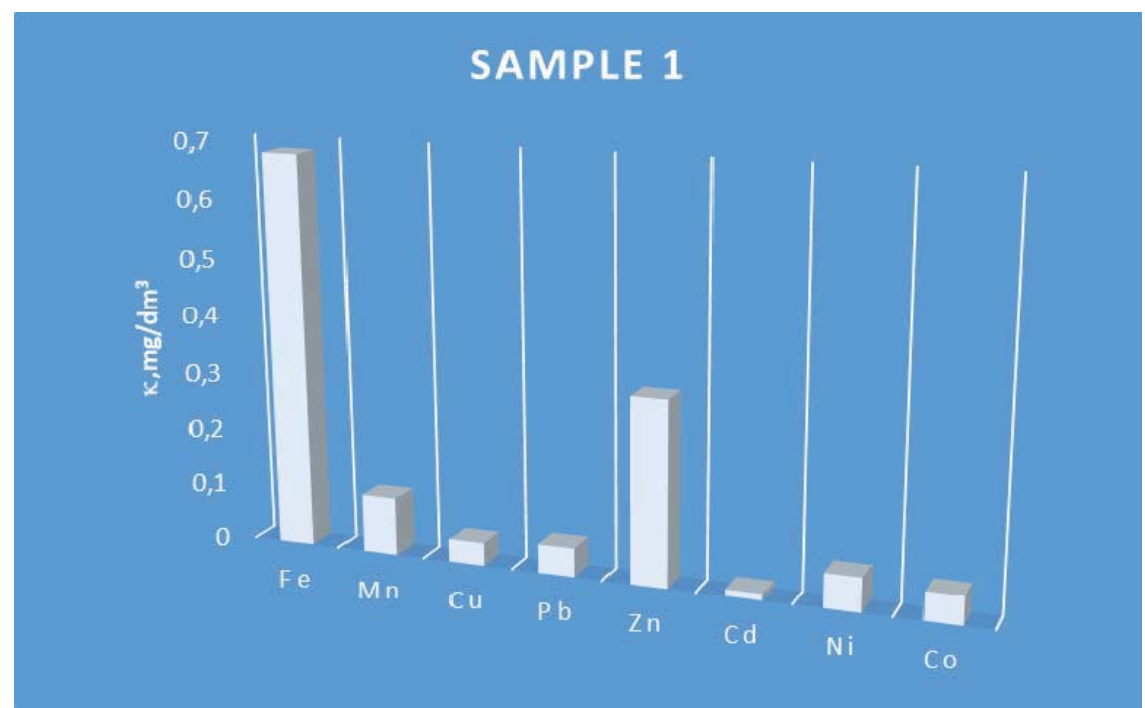

Figure 3 - Neutralization levels with $10 \%$ lime milk and $\mathrm{pH}=9,21$ 


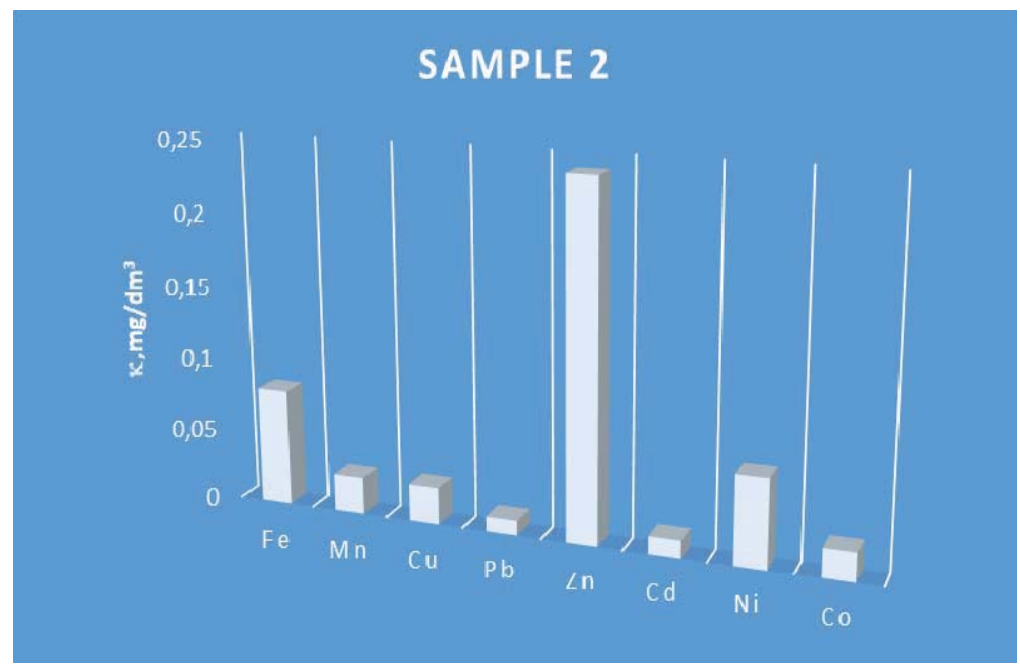

Figure 4 - Neutralization levels with $10 \%$ lime milk and $\mathrm{pH}=10,3$

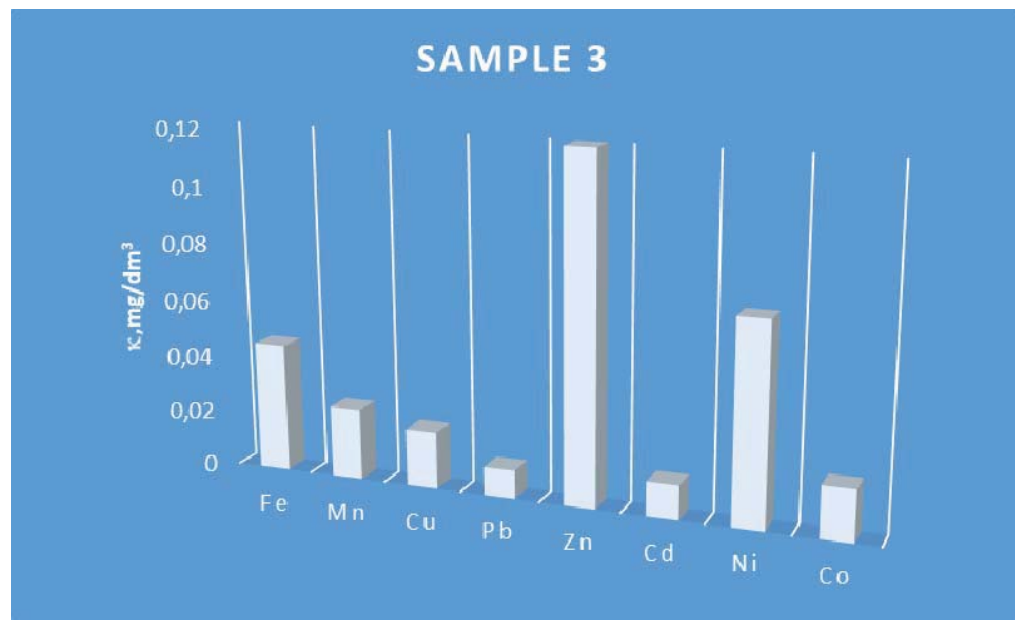

Figure 5 - Neutralization levels with $10 \%$ lime milk and $\mathrm{pH}=10,04$

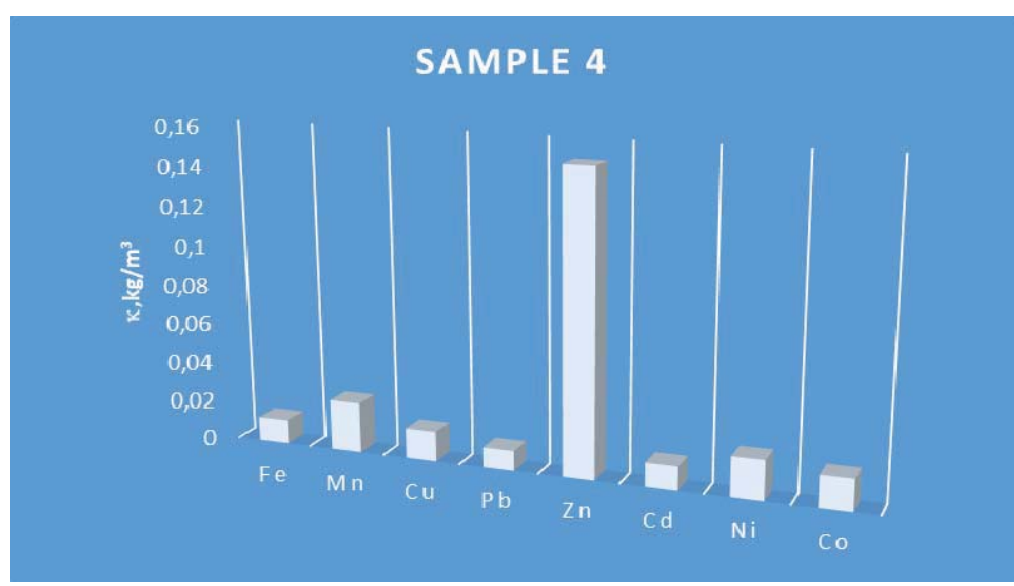

Figure 6 - Neutralization levels with 10\% sodium hydroxide and $\mathrm{pH}=10,04$ 


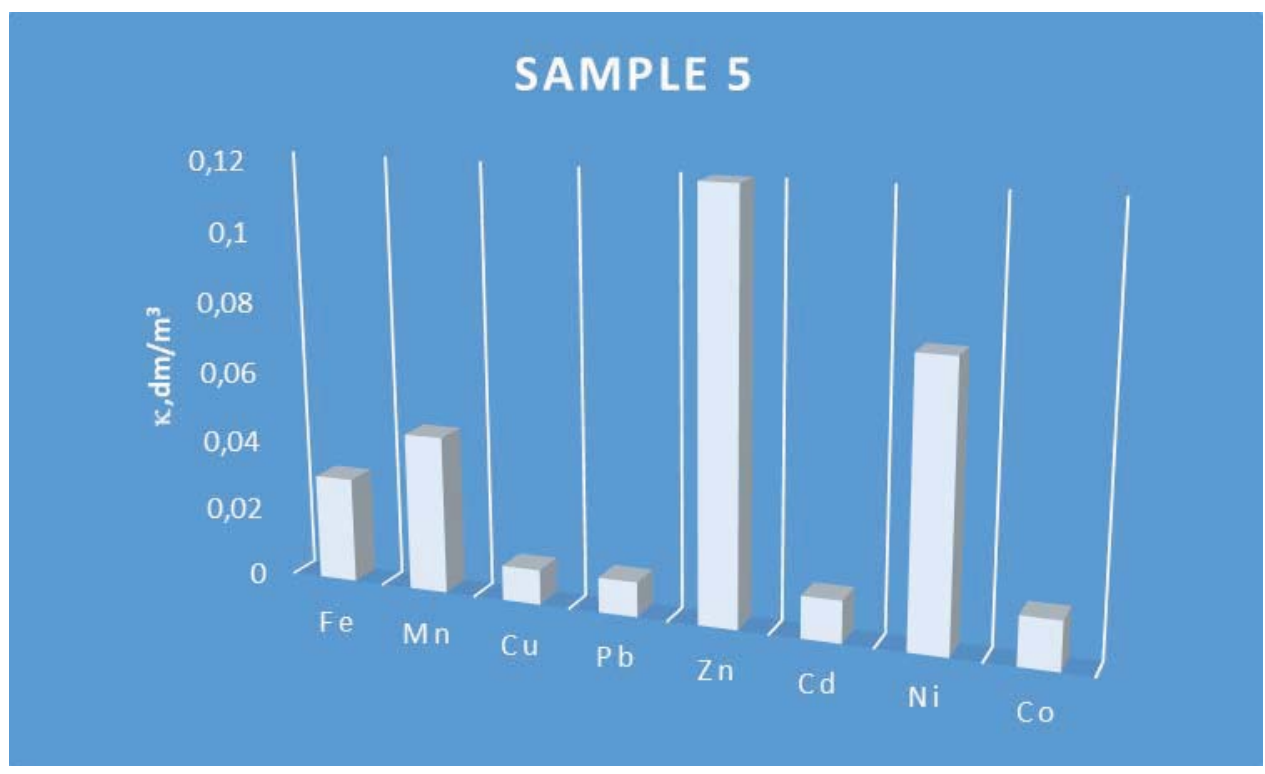

Figure 7 - Neutralization levels with $10 \%$ hydroxide and $\mathrm{pH}=10,95$

Figure. 8 and 9 show laboratory tests for neutralization of samples of acid mine waters with $10 \%$ suspension of lime milk in direct determination of the main indicators of sedimentation and sedimentation of the separated sludge with or without flocculant.

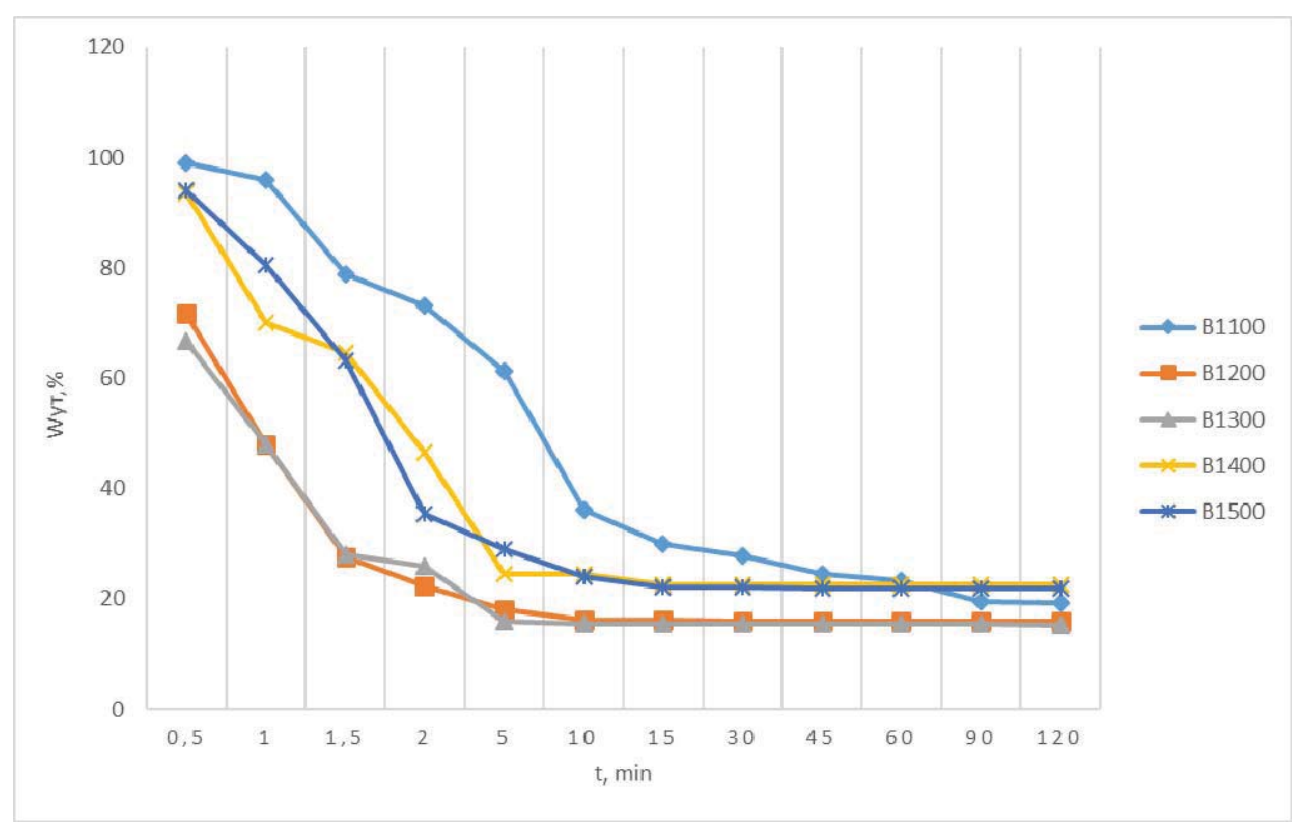

Figure 8 - Sludge volume in different samples 


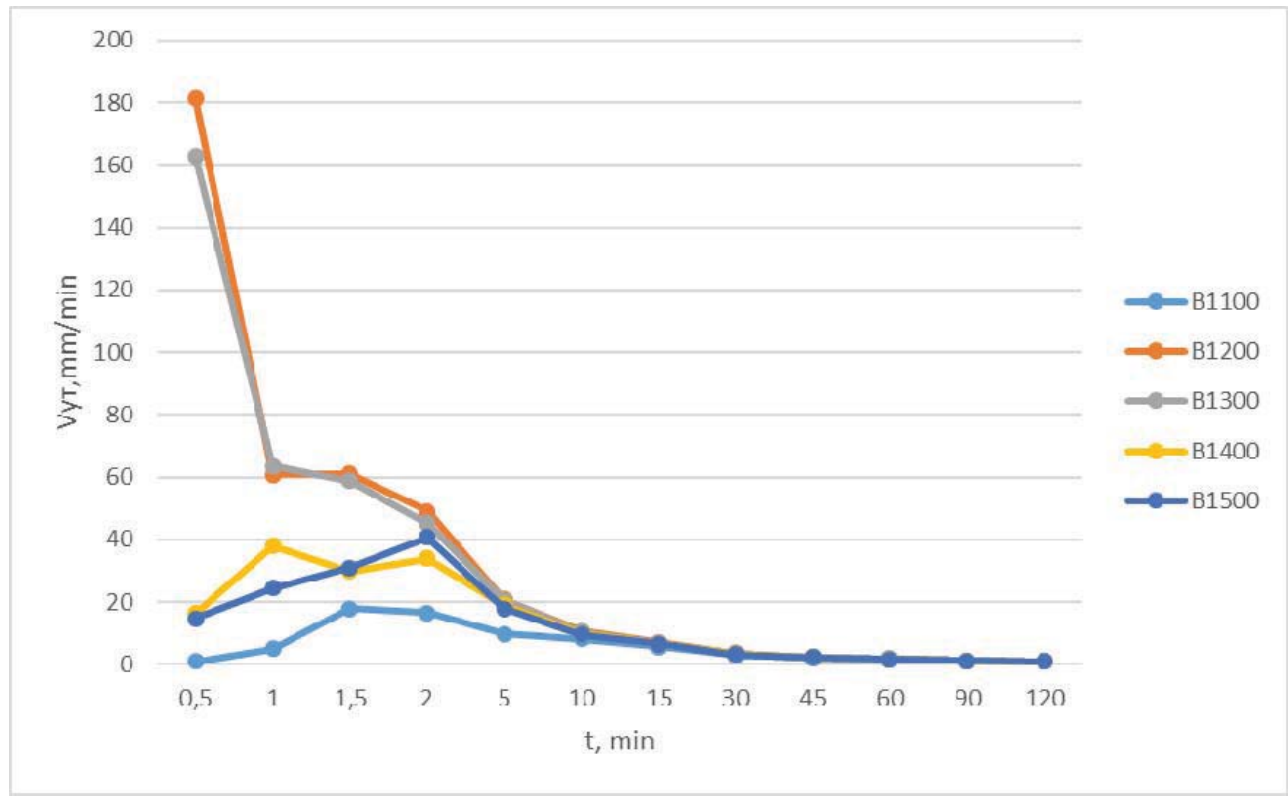

Figure 9 - Sedimentation velocity for different samples

Sample 1100 is neutralized only without the use of a flocculant; sample 1200 was treated with lime milk to $\mathrm{pH}-10,40$ and then with the flocculant MAGNAFLOC 155 at a dose of 1,2 $\mathrm{mg} / \mathrm{dm}^{3}$ (ppm); sample 1300 was treated with lime milk to $\mathrm{pH}-9,50$ and then with the flocculant MAGNAFLOC 338 at a dose of $1,2 \mathrm{mg} / \mathrm{dm}^{3}$ (ppm); sample 1400 was treated with lime milk to $\mathrm{pH}-10,65$ and then with the flocculant MAGNAFLOC 342 at a dose of $0,6 \mathrm{mg} / \mathrm{dm}^{3}$ (ppm) and sample 1500 was treated with lime milk to $\mathrm{pH}-11,22$ and then with the flocculant MAGNAFLOC 155 at a dose of $0,6 \mathrm{mg} / \mathrm{dm}^{3}(\mathrm{ppm})$. In addition to the turbidity of the initial sample after neutralization - in ${ }^{\circ} \mathrm{C}$ by the method of Clarity Ball and respectively the reported flocculation score in the table are given data on the volume of sediment formed - in $\%$ and the sedimentation pattern, defined as sedimentation rate.

Figures 10 and 11 show the summarized results of the laboratory tests for neutralization of acid mine water samples with $10 \%$ sodium hydroxide solution or with $10 \%$ lime milk suspension in direct determination of the main indicators for sedimentation and sedimentation of the separated sludge. with or without flocculant. Sample 1600 is only after neutralization with sodium hydroxide without the use of flocculant; sample 1700 was treated with $10 \%$ sodium hydroxide solution to $\mathrm{pH}-10,70$ and then with the flocculant MAGNAPLOC 342 at a dose of $1,5 \mathrm{mg} / \mathrm{dm}^{3}(\mathrm{ppm})$; sample 1800 was treated with $10 \%$ sodium hydroxide solution to $\mathrm{pH}-10,74$ and then with the flocculant MAGNAFLOC 338 at a dose of $1,5 \mathrm{mg} / \mathrm{dm}^{3}(\mathrm{ppm})$; sample 1910 was treated with lime milk to $\mathrm{pH}-10,33$ and then with the flocculant MAGNAFLOC 342 at a dose of $1,5 \mathrm{mg} / \mathrm{dm}^{3}(\mathrm{ppm})$ and sample 1920 was treated with lime milk to $\mathrm{pH}-11,22$ together with the flocculant MAGNAFLOC 155 at a dose of $1,5 \mathrm{mg} / \mathrm{dm}^{3}$ (ppm), after which the same dose of flocculant was added. In addition to the indicators of turbidity of the initial sample after neutralization - in ${ }^{\circ} \mathrm{C}$ by the method of Clariti Ball and respectively the reported flocculation score, the table also gives data on the volume of sediment formed - in $\%$ and the sedimentation pattern, defined as sedimentation rate. - in $\mathrm{mm}-1 / \mathrm{min}$ for up to 120 minutes. The final moisture of the raw sludge is also taken into account. 


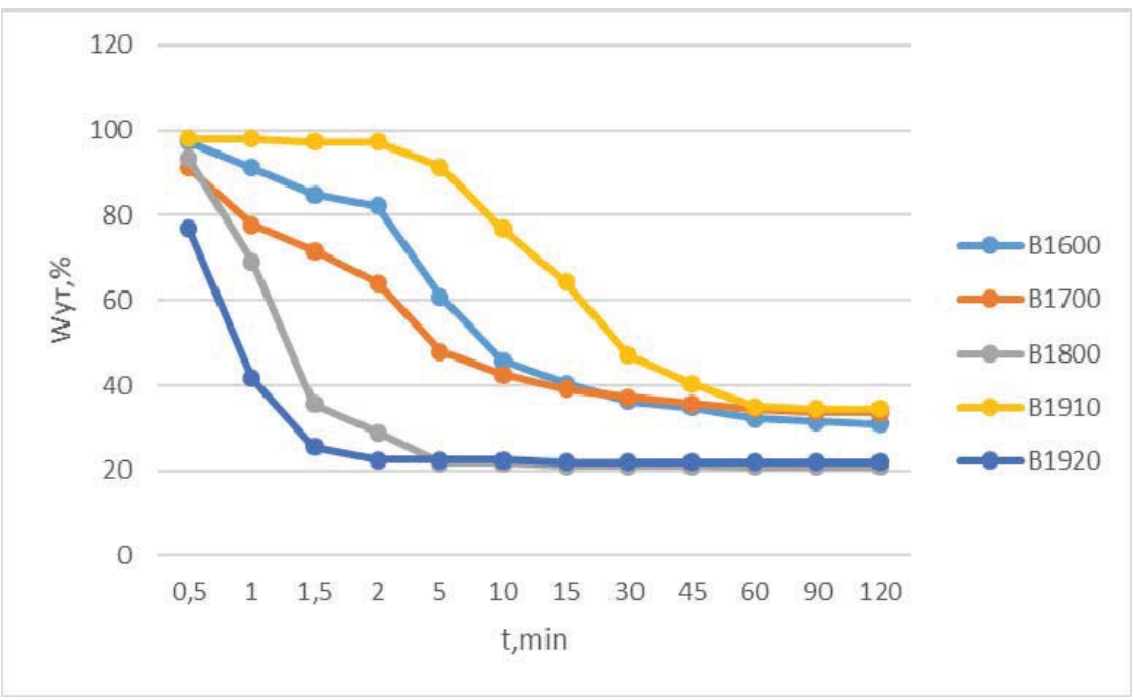

Figure 10 - Sludge volume in different samples

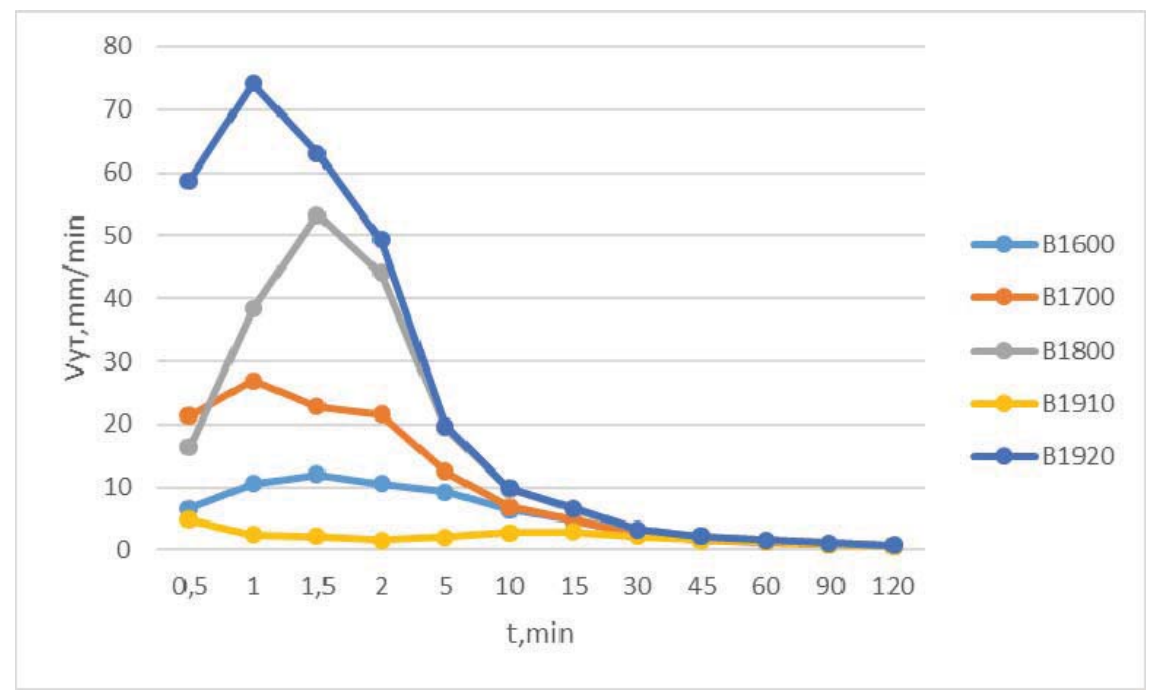

Figure 11 - Sedimentation velocity for different samples

\section{Conclusion}

For the presented experimental results can be made the follow conclusion: To accelerate the sedimentation processes and conditioning the sludge released during the neutralization process, containing mainly calcium sulfate precipitate and metal hydroxides, the anionic flocculant MAGNAFLOC 338 should be used at effective doses of $1,5-2,5 \mathrm{mg} / \mathrm{dm}^{3}$ fed as $0,05 \%$ solution immediately in the last stage of stirring during neutralization, and there should be no stirring in the chamber after feeding the flocculant. When carrying out the neutralization as described above, it can be expected to take into account an effective time for almost complete utilization of the lime milk and reaching the set level of active reaction $\mathrm{pH}$ of about 10 of about 15 minutes, after which the formed calcium suspension sulphateprecipitate and metal hydroxides (mainly ferric and ferrous hydroxides) should be fed 
directly to precipitators to settle and separate the sludge such as the lower drain and the treated water as the upper drain.

The paper is published with the support of the project helping $\mathrm{PhD}$ students 192ПД0024-02 "Development of a specialized test-rig for experimental study of mining waters" Research and Development Sector at the Technical University of Sofia.

\section{References}

1. F. Spellman, Hydraulic Fracturing Wastewater : Treatment, Reuse, and Disposal 1st Edition, ISBN-13:978-1138197923

2. L. Gergov, V. Ivanov. Z. Gergova, I. Ganev, Rectifier $13 \mathrm{kA}$ for electrolysis with two reactors, IV Scientific Conference EF2012, Sozopol, 28 September-1 October 2012, Collection of Reports 2, pp.54-60, (2012)

3. St. Grudev, I. Spassova, M. Nikolova, Module II "Generating, Prevention and Treatment of Mining Water", University of Mining and Geology, Sofia (2005)

4. T. Angelov, I. Grigorova, Iv. Nishkov, A review of the techniques for treatment of sewage drainage waters, Collection of Scientific Confrontation with International Participation "Science in the Globalization Conditions", Kardzhali , pp. 617-621 (2014)

5. I. Antonov, M. Angelov, L. Elenkov, M. Mihaylov, A. Terziev, S. Antonov, Results from numerical experiment during a two-phase jet flow in a filtering medium, Scientific Conference with International Participation "Food Science, Engineering and Technology - 2008, University of Food Technology - Plovdiv, Scientific Papers, vol. LV. 2, 24 - 25, pp. $183-188$, (2008)

6. I. Antonov, A. Terziev, S. Antonov, Distribution of a two-phase turbulent jet in a porous medium. Part 1. Physical and Mathematical Model of the Current, XIV International Scientific and Technical Conference - 2007, Angel Kanchev Regional University - Ruse, Scientific Papers, 46, series 1, ISSN 1311-33-21, p. 82 - 86, (2007)

7. I. Antonov, A. Terziev, S. Antonov, Propagation of a two-phase turbulent jet in a porous medium. Part 2. Results of the numerical experiment, XIV International Scientific and Technical Conference - 2007, RU "Angel Kanchev" - Ruse, Scientific papers, 46, series 1, ISSN 1311-33-21, p. 87 - 90 (2007)

8. P. Kostov, R. Petrova, K. Atanasov, N. Krystev, Energy Consumption and Its Influence on the Environment and Eco-Systems, Proceedings of the C\&SEE International Solid Waste Management Symposium, Issue of TU - Vienna, Institute of Thermodinamics and Energy Conversion, page 107, at the Contract 4-23-2008 of the Project "Environmentally Usage of Power", Vienna, Austria, (2009)

9. R. Petrova, P. Kostov, K. Atanasov, N. Krystev, Basics of Waste Management, Proceedings of the C\&SEE International Solid Waste Management Symposium, Issue of TU - Vienna, Institute of Thermodinamics and Energy Conversion, page 92, at the Contract 4-23-2008 of the Project "Environmentally Usage of Power", Vienna, Austria, (2009)

10. P. Kanchev, I .Ganev, P. Ugrinov, B. Dimitrov, Influence of alloying elements and heat treatment on the properties of gasfield steel 90, Proceedings of XXV - ISTC with international participation "ADP - 2016", pp. 118-224, ISSN 1310 - 3946, (2016)

11. http://www.pollutionissues.com/Li-Na/Mining.html\#ixzz5hn6sK5Kr, Accessed on date 30 October, 2020

12. https://www.moew.government.bg/bg/vodi/Accessed on date 30 October, 2020 